\title{
Automatic Detection and Delimitation of Internal Moisture in Mosaics from Thermographic Sequences. Experimental Tests ${ }^{\dagger}$
}

\author{
Iván Garrido ${ }^{1, *}$, Susana Lagüela ${ }^{2}$, Stefano Sfarra ${ }^{3}$, Hai Zhang ${ }^{4}$ and Xavier P.V. Maldague ${ }^{4}$ \\ 1 Applied Geotechnologies Research Group, Mining \& Energy Engineering School, University of Vigo, \\ Rúa Maxwell s/n, 36310 Vigo, Spain \\ 2 TIDOP Research Group, EPS Ávila, University of Salamanca, Calle Hornos Caleros 50, 05003 Ávila, Spain; \\ sulaguela@usal.es \\ 3 Department of Industrial and Information Engineering and Economics (DIIIE), University of L'Aquila, \\ Piazzale E. Pontieri 1, I-67100 Monteluco di Roio, L'Aquila, Italy; stefano.sfarra@univaq.it \\ 4 Computer Vision and Systems Laboratory, Department of Electrical and Computer Engineering, \\ Université Laval, 1065, av. de la Médecine, Québec, QC, G1V 0A6, Canada; hai.zhang.1@ulaval.ca (H.Z.); \\ xavier.maldague@gel.ulaval.ca (X.P.V.M.) \\ * Correspondence: ivgarrido@uvigo.es \\ + Presented at the 15th International Workshop on Advanced Infrared Technology and Applications (AITA \\ 2019), Florence, Italy, 17-19 September 2019.
}

Published: 17 September 2019

\begin{abstract}
InfraRed Thermography, IRT, is one of the most recent techniques to monitor heritage elements, finding existing pathologies in order to implement the required maintenance tasks. However, most IRT results on cultural heritage are interpreted subjectively. Then, this work presents a methodology for the automatic detection and delimitation of moisture inside a heritage element, a mosaic in this case, from a thermographic sequence, based on the analysis of the temperature distribution of the thermal images acquired. Comparing the experimental test results with typical thermographic algorithms, the detection performance of the algorithm proposed was similar, but the new method is able to delimit and automate the whole process.
\end{abstract}

Keywords: InfraRed Thermography; image processing; cultural heritage; conservation; mosaic; moisture; automation.

\section{Introduction}

The improvement of technologies, and the appearance of new methodologies, mainly based on Non-Destructive Testing (NDT), is a key aspect for the advanced monitoring of objects and structures belonging to cultural heritage. NDT techniques are very appropriate tools mainly because they neither disturb nor damage the integrity of the target under study. Among them, InfraRed Thermography (IRT) is one of the techniques with best results for moisture analysis.

Moisture in a heritage element can cause its deterioration with relative ease, depending on the water content and environmental conditions. This is because the water breaks the bonds of the molecules of the target affected through its phase changes: i) liquid to solid, which may cause cracking and detachment and, ii) liquid to vapour, which causes the previous negative consequences, in addition to efflorescence, if the moisture contains soluble salts.

Despite the publication of several papers on IRT analysis of moisture, the automation of the interpretation of the thermal images has not been solved, except [1,2]. Thus, this paper presents a new method for the automatic detection and delimitation of the appearance of water inside a heritage 
element from a sequence of thermal images. It is based on the analysis of the temperature distribution of these images.

In the worst and real case, moisture deterioration includes the sinking of the floor of a heritage site at various points, followed by fissuring. This deterioration, in combination with chemical infiltration of the plaster by salts dissolved in water, leads to a loss of cohesion. As a result, components of a heritage element, such as tesserae, become detached from the underlying support. In addition, during in-situ IRT experiments, particular attention should be paid to environmental reflections in case glass tesserae are analysed. Here, the performance of the method is evaluated through its application to a mosaic made by synthetic tesserae, where internal water appears through its recirculation through a pipe and its internal propagation from a sponge. Following sections detail the mosaic and the experiments performed, explain the methodology, analyse the results, and compare them with similar results obtained by some typical thermal image processing algorithms.

\section{Materials and testing configuration}

The mosaic under study corresponds to that described in reference [3], which front surface is shown in Figure 1a. This mosaic is manufactured with different artificial internal defects placed at different depths and locations (see Figure 1b): i) dynamic defects: pipe, void and sponge and, ii) static defects: pluriball, piece of iron and fire cone. The internal water appears by recirculation through the pipe, and by propagation from the sponge to be soaked due to connection to an external tube. The third dynamic defect is a void into which compressed air can be injected.

Regarding the testing configuration, two experiments are performed in laboratory conditions, with steps shown in Table 1 . The thermal camera is at a distance of $1.5 \mathrm{~m}$ and $0^{\circ}$ regarding the perpendicular of the front surface of the mosaic, acquiring thermal images with time intervals of $1 \mathrm{~s}$ in both experiments. The characteristics of the water pump for water recirculation and the air compressor ("Air comp." in Table 1) are shown in [3]. The lamp used in the first experiment is a 500 $\mathrm{W}$ halogen lamp, located at the bottom of the mosaic, with $25 \mathrm{~cm}$ elevation and $14 \mathrm{~cm}$ separation, heating the mosaic at an angle of inclination of $17^{\circ}$ regarding the upper vertical axis.

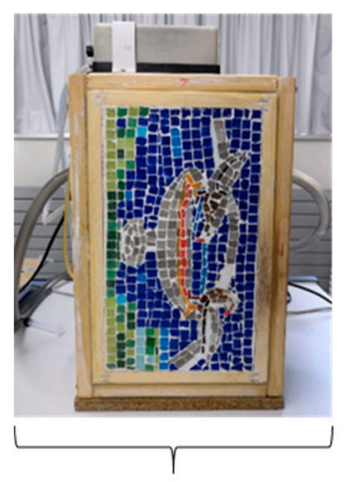

(a)

(1)

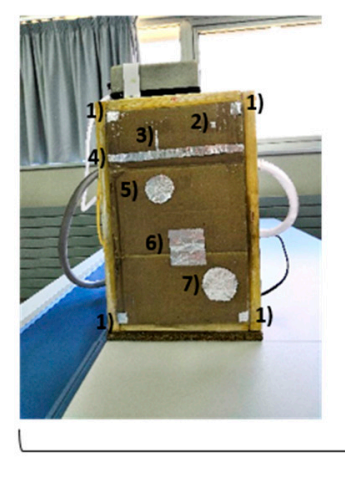

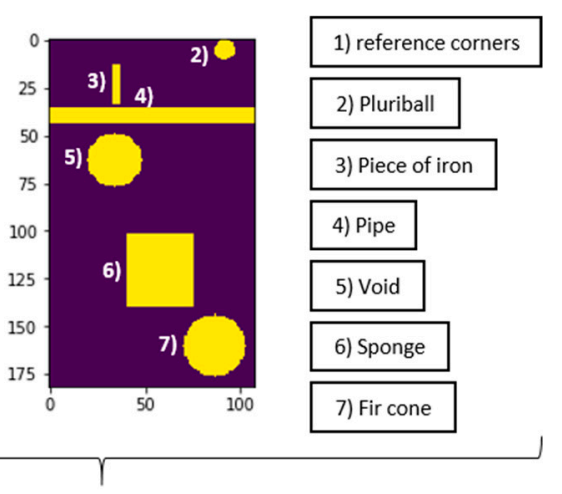

(b)

Figure 1. (a) Mosaic to be tested, seen from its front surface; (b) Frontal representation of the situation of each of the artificial internal defects. 
Table 1. Steps followed in the two experiments performed in this paper ("Ta" = ambient temperature $\left({ }^{\circ} \mathrm{C}\right)$, "Т $\mathrm{T}_{22} \mathrm{O}^{\prime}=$ water temperature $\left({ }^{\circ} \mathrm{C}\right)$ and " $\mathrm{RH}^{\prime \prime}=$ relative humidity $\left.(\%)\right)$.

\begin{tabular}{|c|c|c|c|c|c|c|c|c|}
\hline \multirow{2}{*}{ Tests } & \multicolumn{8}{|c|}{ Time in $\mathrm{s}$} \\
\hline & 0 & 120 & 300 & 360 & 420 & 600 & 660 & 720 \\
\hline $\begin{array}{c}\text { Test } 1 \\
\mathrm{Ta}=26 \\
\mathrm{RH}=40.7\end{array}$ & $\begin{array}{l}\text { Thermal camera } \\
\text { ON } \\
\text { Water pump ON } \\
\left(\mathrm{T}_{\mathrm{H} 2 \mathrm{O}}=12.5\right)\end{array}$ & $\begin{array}{c}\text { Lamp } \\
\text { ON }\end{array}$ & $\begin{array}{l}\text { Air } \\
\text { Comp. } \\
\text { ON }\end{array}$ & $\begin{array}{l}\text { Air } \\
\text { Comp. } \\
\text { OFF }\end{array}$ & $\begin{array}{c}\text { Water } \\
\text { injection to } \\
\text { sponge }(50 \mathrm{ml} \text {, } \\
\text { Т } 20=11)\end{array}$ & $\begin{array}{l}\text { Air } \\
\text { Comp. } \\
\text { ON }\end{array}$ & $\begin{array}{l}\text { Air } \\
\text { Comp. } \\
\text { OFF }\end{array}$ & $\begin{array}{c}\text { Thermal camera } \\
\text { OFF } \\
\text { Water pump } \\
\text { OFF (TH2O = 17) } \\
\text { Lamp OFF }\end{array}$ \\
\hline $\begin{array}{c}\text { Test } 2 \\
\mathrm{Ta}=23.3 \\
\mathrm{RH}=37.7\end{array}$ & $\begin{array}{c}= \\
\left(\mathrm{T}_{\mathrm{H} 2 \mathrm{O}}=12.3\right)\end{array}$ & $X$ & $=$ & $=$ & $=$ & $=$ & $=$ & $\begin{array}{c}= \\
\left(\mathrm{T}_{\mathrm{H} 2 \mathrm{O}}=14.7\right)\end{array}$ \\
\hline
\end{tabular}

\section{Methodology}

According to [1], the different thermal behaviours between a moisture area and its unaltered environment results in the conversion of a unimodal temperature distribution of the thermal image under study, typical of defect-free elements, to a pseudo-bimodal temperature distribution. Then, in this work, the automatic detection and delimitation of the appearance of moisture inside a heritage element is performed from a sequence of thermal images based on two consecutive thermal criteria:

1. Calculation and summation of the skew and kurtosis values of the temperature distribution of each thermal image acquired, in order to search pronounced maximum peaks regarding the result of the sum and throughout the entire sequence under study, with a magnitude always greater than one (henceforth maximum temporal instances).

2. Search for inequalities in the shape of the temperature distribution of the thermal images corresponding to those maximum temporal instances found by the $1^{\text {st }}$ criterion, regarding the first thermal image corresponding to the initial instant of the sequence, considering this instant without internal moisture.

With the 1st criterion, the objective is to determine automatically the instants when the thermal camera is able to capture the footprint of a possible apparition of internal moisture, since a unimodal temperature distribution presents values of skew and kurtosis equal to zero. With the 2nd criterion, the aim is at automatically delimit the possible internal moisture areas found by the 1st criterion.

\section{Results and discussion}

The results of the 1st and 2nd thermal criteria proposed in this methodology for the mosaic under study are shown in Figure 2. Figure 3 shows the results corresponding to the best Signal-toNoise Ratio (SNR) values obtained by applying typical thermal image processing algorithms to the experiment 2 of [3], which is similar to the tests in this work: Principal Component Thermography (PCT), Partial Least-Squares Thermography (PLST) and Pulsed Phase Thermography (PPT).

From the results of Figure 2, it is contemplated that both the water recirculation zone through the pipe, and the water zone propagated from the sponge, are detected and delimited in their most representative time instants. In addition, despite the existence of four other internal defects in the mosaic, these do not affect the interpretation of the appearance of internal water, due to the lack of an external thermal excitation sufficient for their detection. From a quantitative point of view, average values of precision, recall and F-score of $22 \%, 81 \%$ and $34 \%$ have been obtained, respectively, regarding the delimitation of the two internal water zones, being very similar between them and between the two experiments performed. The low precision value, which also affects F-score, is because only the areas of the pipe and sponge have been considered as true positives, without taking into account the effect they may have on their surroundings. Comparing with the results of Figure 3 , the detection of the appearance of the internal water is contemplated in a similar way, but this new method allows the delimitation of pathological areas, which is not possible in the other algorithms, in addition to working in an automated way. 

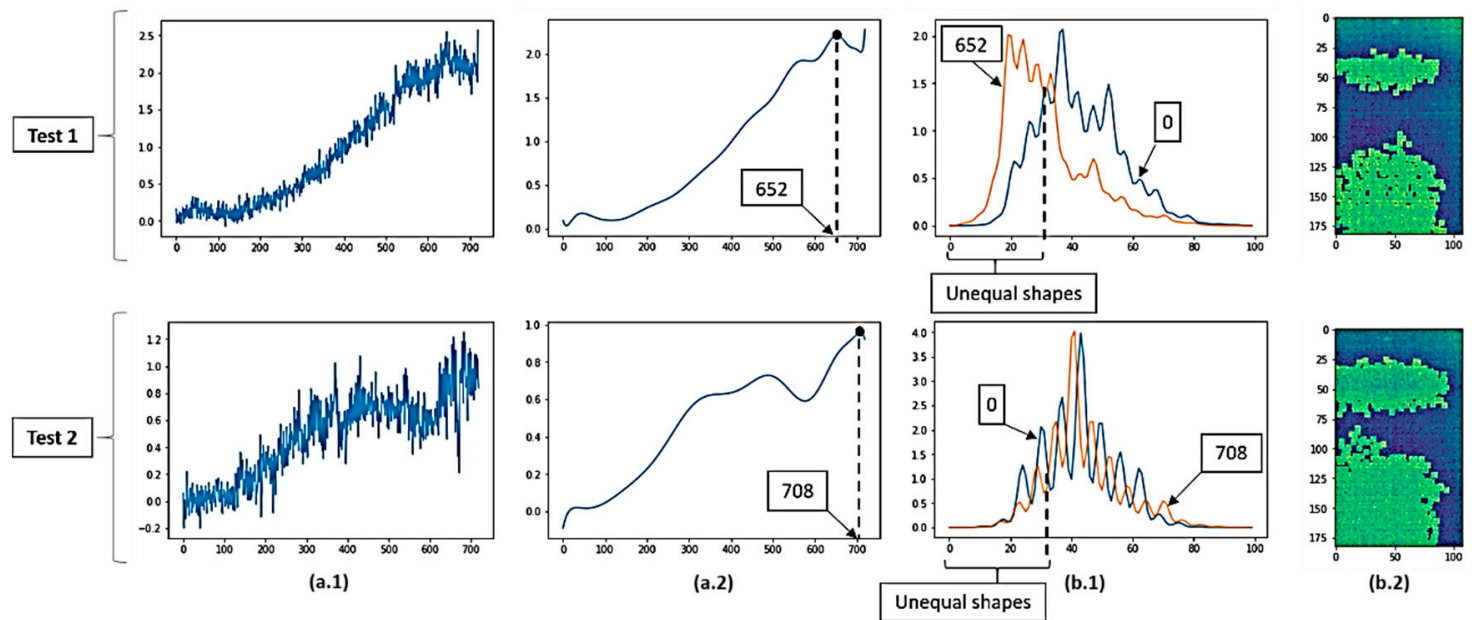

(a.2)

Unequal shapes

(b.2)

Figure 2. (a.1) 1st Criterion: summation of the skew and kurtosis values along each of the sequences; (a.2) 1st Criterion: polynomial adjustment of the sum of skew and kurtosis, searching maximum peaks that meet the 1st criterion (black circles); (b.1) 2nd Criterion: search of unequal shapes between the maximum temporal instances (1st criterion) and the initial temporal instant; (b.2) 2nd Criterion: delimitation of the unequal shapes as green areas.

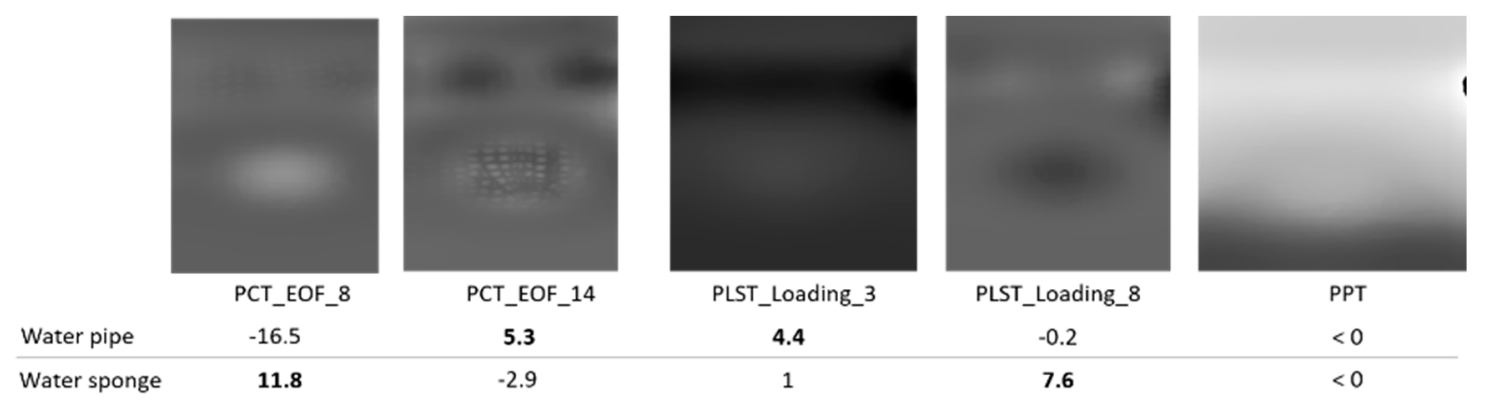

Figure 3. Best SNR results (black numbers) regarding the detection of the water recirculation through the pipe and the water propagation from the sponge, applying PCT, PLST and PPT and following experiment 2 of reference [3]. A description of the methodology here applied can be found in [4].

\section{Conclusions}

This work implies a step forward in the automation of the thermographic inspection process and optimization of the decision-taking for rehabilitation actions in cultural heritage. Future research will deal with the automatic detection and extraction of other types of internal defects, as well as the improvement of the performance of the methodology developed.

Author Contributions: Conceptualization, I.G., S.L.; methodology, I.G.; software, H.Z. and X.P.V.M.; validation, I.G. and H.Z.; investigation, I.G., S.S. and H.Z.; resources, S.S.; writing-original draft preparation, I.G.; writing-review and editing, S.L., S.S., H.Z. and X.P.V.M.

Funding: This research was funded by MINISTRY OF EDUCATION (GOVERNMENT OF SPAIN) through programs for human resources (FPU16/03950), and by the EUROPEAN COMMISSION through the program H2020-FTIPilot-2015-1 to the proposal 720661 - ENGINENCY and the CÁTEDRA IBERDROLA VIII CENTENARIO - UNIVERSITY OF SALAMANCA (SPAIN).

Conflicts of Interest: The authors declare no conflict of interest. 


\section{References}

1. Garrido, I.; Lagüela, S.; Sfarra, S.; Madruga, F.J.; Arias, P. Automatic detection of moistures in different construction materials from thermographic images. J. Therm. Anal. Calorim. 2019, 1-20, doi:10.1007/s10973019-08264-y.

2. Garrido, I.; Lagüela, S.; Arias P. Autonomous thermography: towards the automatic detection and classification of building pathologies. In Proceedings of the 14th Quantitative Infrared Thermography Conference, Berlin, Germany, 25-29 June 2018.

3. Sfarra, S.; Ibarra-Castanedo, C.; Theodorakeas, P.; Avdelidis, N.P.; Perilli, S.; Zhang, H.; Nardi, I.; Koui, M.; Maldague, X.P.V. Evaluation of the state of conservation of mosaics: Simulations and thermographic signal processing. Int. J. Therm. Sci. 2017, 117, 287-315, doi:10.1016/J.IJTHERMALSCI.2017.04.003

4. Sfarra, S.; Yao, Y.; Zhang, H.; Perilli, S.; Scozzafava, M.; Avdelidis, N.P.; Maldague, X.P.V. Precious walls built in indoor environments inspected numerically and experimentally within long-wave infrared (LWIR) and radio regions. J. Therm. Anal. Calorim. 2019, 1-29, doi:10.1007/s10973-019-08005-1.

(C) 2019 by the authors. Licensee MDPI, Basel, Switzerland. This article is an open access article distributed under the terms and conditions of the Creative Commons Attribution (CC BY) license (http://creativecommons.org/licenses/by/4.0/). 